\title{
OCCUPATIONAL CONCERNS ASSOCIATED WITH REGULAR USE OF MICROSCOPE
}

\section{GARIMA JAIN and PUSHPARAJA SHETTY}

\author{
A.B. Shetty Memorial Institute of Dental Sciences, Deralakatte, Mangalore, India \\ Department of Oral Pathology and Microbiology
}

\begin{abstract}
Objectives: Microscope work can be strenuous both to the visual system and the musculoskeletal system. Lack of awareness or indifference towards health issues may result in microscope users becoming victim to many occupational hazards. Our objective was to understand the occupational problems associated with regular use of microscope, awareness regarding the hazards, attitude and practice of microscope users towards the problems and preventive strategies. Material and Methods: a questionnaire based survey done on 50 professionals and technicians who used microscope regularly in pathology, microbiology, hematology and cytology laboratories. Results: Sixty two percent of subjects declared that they were suffering from musculoskeletal problems, most common locations being neck and back. Maximum prevalence of musculoskeletal problems was noted in those using microscope for 11-15 years and for more than $30 \mathrm{~h} /$ week. Sixty two percent of subjects were aware of workplace ergonomics. Fifty six percent of microscope users took regular short breaks for stretching exercises and 58\% took visual breaks every 15-30 min in between microscope use sessions. As many as 94\% subjects reported some form of visual problem. Fourty four percent of microscope users felt stressed with long working hours on microscope. Conclusions: The most common occupational concerns of microscope users were musculoskeletal problems of neck and back regions, eye fatigue, aggravation of ametropia, headache, stress due to long working hours and anxiety during or after microscope use. There is an immediate need for increasing awareness about the various occupational hazards and their irreversible effects to prevent them.
\end{abstract}

Key words:

Occupational hazards, Microscope use, Ergonomics, Musculoskeletal problems

\section{INTRODUCTION}

Occupations in any field may use up all the energy, health and patience of an individual, and occupational problems may take their toll on the well-being and feeling of satisfaction in the employee [1]. Oxford English Dictionary defines an occupational hazard as "a risk accepted as a consequence of a particular occupation" [2]. The development and implementation of some rules and regulations by concerned administrative bodies for every profession may help reduce these unpleasant experiences.
A number of highly trained medical professionals and technicians may help doctors to make decisions and save lives [3]. One such group comprises those who use microscope as a tool of investigation [3]. Microscope users may be unaware or may neglect the health risks associated with their work and fall prey to a number of occupational problems [3].

The association of prolonged microscope use with the development of chronic pain syndromes and visual problems has been recognized for decades, yet awareness about these occupational hazards comes only when a person becomes victim to these hazards [4].

Received: December 16, 2013. Accepted: April 14, 2014.

Corresponding author: G. Jain, Department of Oral Pathology and Microbiology, A.B. Shetty Memorial Institute of Dental Sciences, Deralakatte, Mangalore (e-mail: drgarimajain7@gmail.com). 
Work related Musculoskeletal disorders (MSDs), also known as cumulative trauma disorder, occur in microscope users due to excessive force, repetitive movement, awkward posture, prolonged static posture or vibration [4]. According to statistics of National Safety Council 2006 and Straker et al. (2004), out of all injuries which prevent an employee from attending work, MSDs are the reason in approximately one third cases [5].

Ergonomics is identified as an emerging area of practice. As told by OSHA, it deals with fitting a job to a person that helps lessen muscle fatigue, increases productivity and reduces the number and severity of work-related MSDs [6]. In microscope users, repetitive eye movements while screening slides, difficulty in accommodation and convergence of eye can result in fatigue, eye strain, and visual discomfort. These problems can also be linked to monotony and prolonged working time without a break $[7,8]$.

The more unexplored areas of occupational hazards with regular microscope use are stress, burnout, depression and anxiety among such personnel.

In the present questionnaire based study, an effort has been made to understand the occupational concerns in the population of microscope users as well as their knowledge, awareness and attitude about occupational problems like musculoskeletal disorders, visual problems and stress. The opinion of the subjects included in study about their working environment and comfort levels have also been voiced.

\section{MATERIAL AND METHODS}

This study is based on a questionnaire comprising 40 questions. It aimed to include all professionals who used microscope regularly, like pathologists, microbiologists, oral pathologists, post-graduate students and technicians in pathology, microbiology, hematology and cytology laboratories. The questionnaires were given in person, explaining the objective of the study. Every questionnaire had an informed consent form attached to it. Filled questionnaires with informed consent form duly signed, were later collected. Fifty microscope users answered the questionnaire.

\section{Statistical analysis \\ Data collected was subjected to statistical analysis including frequency analyses, $\mathrm{Chi}^{2}$ test and Fisher's exact tests.}

\section{RESULTS}

\section{Participation}

Thirty three females and 17 males (total: 50) with an age range of 23-70 years (mean: 33.62 years) participated in the study. Twenty four participants were below 30 years, 17 between 31-40 years and 9 were above 40 years. Out of the 50 subjects, 13 were pathologists, 6 microbiologists, 8 oral pathologists, 13 postgraduate students and 10 technicians in pathology, hematology and microbiology laboratories. The questionnaire survey has been summarized in Table 1 and work place specifications as asked in the questionnaire have been briefed in Table 2.

\section{Questionnaire \\ Musculoskeletal disorders}

Sixty two percent of the microscope users in this study declared that they were suffering from musculoskeletal problems and 58\% of them faced it repetitively. The most common locations were neck and back (Figure 1). Other problematic areas included shoulder, wrist and hand.

There was a statistically significant difference in overall prevalence of musculoskeletal problems with maximum in those using microscope for 11-15 years $(\mathrm{p}=0.029)$ and, surprisingly, less subjects in the groups using microscope for more than 15 years reported musculoskeletal problems. All the subjects who used microscope for more than $30 \mathrm{~h}$ per week said that they were victims of musculoskeletal problems, followed by $60 \%$ (21-30 h/week), $52.4 \%$ (1-10 h/week) and 44.4\% (11-20 h/week). 
Table 1. Questionnaire survey summary

\begin{tabular}{|c|c|c|}
\hline \multirow[t]{2}{*}{ Characteristic } & \multicolumn{2}{|c|}{$\begin{array}{l}\text { Respondents } \\
(\mathrm{N}=50)^{*} \\
(\%)\end{array}$} \\
\hline & yes & no \\
\hline Ever experienced work-related musculoskeletal problems & $31(62.00)$ & $19(38.00)$ \\
\hline Repetitive attacks of musculoskeletal problems & $18(58.06)^{*}$ & $13(41.93)^{*}$ \\
\hline Taken sick leave due to musculoskeletal problem & $2(6.45)^{*}$ & $29(93.55)^{*}$ \\
\hline Taken any form of treatment/hospitalization for musculoskeletal problems & $7(22.60)^{*}$ & $24(77.42) *$ \\
\hline Take regular short breaks for stretching exercises & $28(56.00)$ & $22(44.00)$ \\
\hline Aware of work place ergonomics & $31(62.00)$ & $19(38.00)$ \\
\hline Suffering from any known ametropia & $30(60.00)$ & $20(40.00)$ \\
\hline Aggravation of ametropia during working years on microscope & $18(36.00)$ & $32(64.00)$ \\
\hline Experiencing eye fatigue during microscope use & $28(56.00)$ & $22(44.00)$ \\
\hline Experiencing headache during microscope use & $24(48.00)$ & $26(52.00)$ \\
\hline Taking visual breaks every $15-30 \mathrm{~min}$ in between microscope use & $29(58.00)$ & $21(42.00)$ \\
\hline Getting regular ophthalmic check up done & $23(46.00)$ & $27(54.00)$ \\
\hline Difficulty in viewing the microscope with spectacles & $9(18.00)$ & $41(82.00)$ \\
\hline Signed off from work due to visual problems & $4(8.00)$ & $46(92.00)$ \\
\hline Stressed due to long hours spent on microscope & $22(44.00)$ & $28(56.00)$ \\
\hline Find reporting of microscopic findings and final diagnosis stressful & $13(26.00)$ & $37(74.00)$ \\
\hline Feel anxious/irritated while or after using microscope & $14(28.00)$ & $36(72.00)$ \\
\hline Feel depression or burnout due to regular microscope use & $13(26.00)$ & $37(74.00)$ \\
\hline Aware of CDC guidelines for microscope use & $18(36.00)$ & $32(64.00)$ \\
\hline Satisfied with comfort levels of workplace/microscope & $37(74.00)$ & $13(26.00)$ \\
\hline
\end{tabular}

CDC - Centres for Disease Control and Prevention.

* Except for marked values, where $\mathrm{N}=31$ (values and $\%$ are out of 31 ).

Table 2. Workplace specifications

\begin{tabular}{lcc}
\hline & Office & \multicolumn{2}{c}{$\begin{array}{c}\text { Respondents } \\
(\mathrm{N}=50) \\
(\%)\end{array}$} \\
\hline At least one window & yes & no \\
Air conditioning & $40(80.0)$ & $10(20.0)$ \\
Shared with colleagues & $21(42.0)$ & $29(58.0)$ \\
Microscopes very closely placed & $50(100.0)$ & $0(0.0)$ \\
Microscope & $21(42.0)$ & $29(58.0)$ \\
$\quad$ tube adjustable in height & & \\
$\quad$ allows horizontal line of sight & $13(26.0)$ & $37(74.0)$ \\
ergonomically optimized chairs & $19(38.0)$ & $31(62.0)$ \\
regularly serviced & $31(62.0)$ & $19(38.0)$ \\
\hline
\end{tabular}




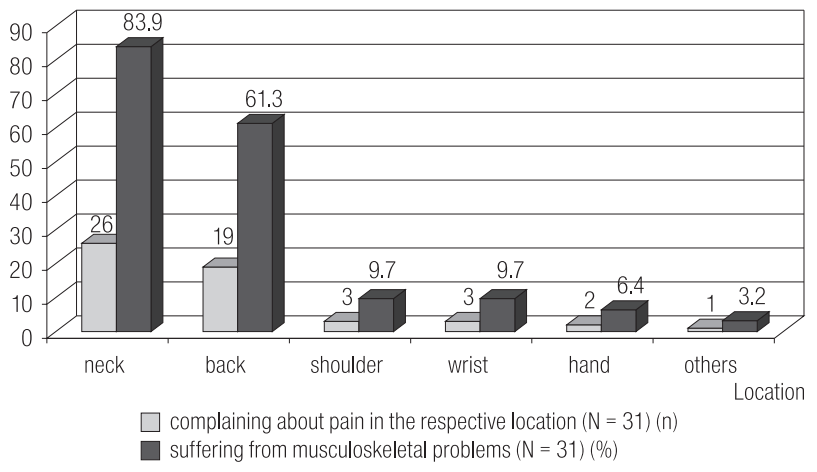

Fig. 1. Location of musculosceletal problems in microscope users

Sixty two percent of subjects were aware of workplace ergonomics but awareness about the Centres for Disease Control and Prevention (CDC) guidelines for microscope use was as low as $36 \%$.

Only $6 \%$ of those suffering took 1-2 days of sick leave during the past year. Those who took sick leave were all males who belonged to the age group of more than 40 years and who spent more than $30 \mathrm{~h} /$ week using microscope for more than 15 years. Twenty three percent of those suffering had to take some form of treatment or hospitalization.

Fifty six percentage microscope users in our survey took regular short breaks for stretching exercises and 58\% took visual breaks every 15-30 min in between microscope use. Only $62 \%$ subjects enjoyed the luxury of ergonomically optimized chairs.

There was no statistically significant association between overall prevalence of musculoskeletal problems or their repetitive nature, and factors like the habit of taking regular short breaks for stretching exercises, adjustable and ergonomically optimized chairs, adjustability of microscope tube or microscope allowing horizontal line of sight, awareness about work place ergonomics and CDC guidelines for microscope use.

We also did not find any significant association between age, gender and profession with musculoskeletal problems or their repetitive attacks.

\section{Visual problems}

In our study group, $60 \%$ subjects claimed to suffer from refractive errors. Sixty percent ametropic microscope users reported an aggravation of ametropia during their working years, out of which $33.3 \%$ believed that microscope use was the sole reason for this aggravation. Thirty two percent of microscope users experienced both visual and musculoskeletal problems simultaneously.

As many as $94 \%$ subjects mentioned some form of visual problem or a combination, ranging from eye discomfort $(38.3 \%)$, headache $(51.1 \%)$, dry eye $(12.8 \%)$ with maximum subjects complaining of eye fatigue (59.6\%) during microscope use (Figure 2).

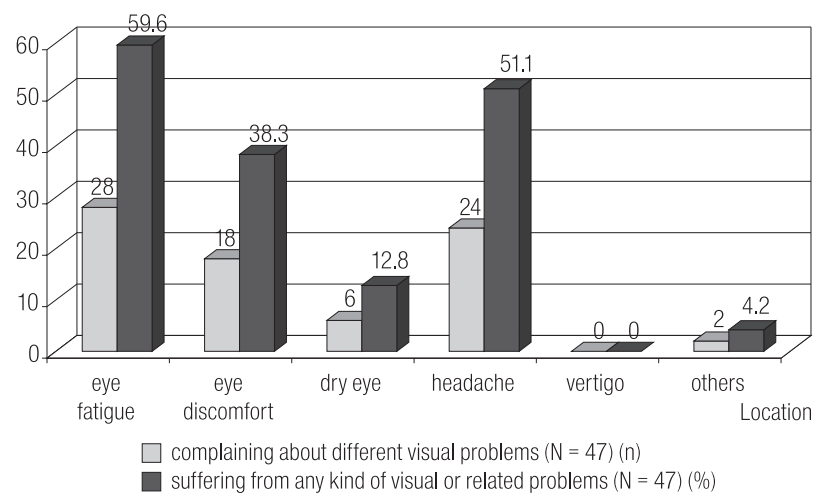

Fig. 2. Different visual problems among microscope users

None of the factors like habit of taking visual breaks every 15-30 min in between microscope use, number of years of microscope use, weekly working hours, or whether they used spectacles while looking into the microscope or not made a statistically significant difference in aggravation of ametropia.

\section{Stress}

Fourty four per cent of microscope users felt stressed with long working hours on microscope, out of which $26 \%$ considered it due to physical fatigue only. Twenty six percentage found the reporting of microscopic findings and final diagnosis as a cause of stress while $52 \%$ found the lack of 
achievement of final diagnosis to be stressful. According to the information disclosed in the questionnaire, males experienced significantly higher stress than females $(p=0.007)$. Eight per cent of microscope users always felt anxious and irritated during or after using microscope while $20 \%$ felt the similar way only a few times. Twenty six percent felt depressed and burnout after using microscope. There was a statistically significant association between no. of hours of microscope use per week and stress, with complaint of feeling anxious/irritated during or after microscope use and feeling depressed/burnout recorded among maximum subjects belonging to the group using microscope for more than $30 \mathrm{~h} /$ week.

Factors like age, number of years of microscope use, talking to colleagues while reporting, (whether subject matters or otherwise) did not seem to have an influence on work related stress.

\section{Satisfaction with workplace}

Eighty percent of subjects had at least one window in their microscope room, while $42 \%$ enjoyed air conditioned microscope rooms. All the subjects shared the microscope use area with their colleagues. Forty two percent of microscope users reported that their microscopes were very closely placed. In spite of these conditions, only $18 \%$ of them thought that they did not have enough place to sit comfortably. Seventy percentage informed that their microscopes were serviced regularly. Only $62 \%$ subjects enjoyed the luxury of adjustable and ergonomically optimized chairs.

Seventy four percent of subjects were satisfied with the comfort levels of their workplace with statistically significant association with those having at least one window in their microscope room or air conditioned rooms, enough place to sit comfortably, adjustable chairs and those provided the privilege of regular servicing of microscopes.

Eighty two percent of subjects were satisfied with their working environment.

\section{DISCUSSION}

This study indicates that there are various work related problems, lack of awareness and ignorance among microscope users, which, if not dealt suitably with, may make their profession a burden rather than a boon.

In the present study, the prevalence of musculoskeletal problems among microscope users was high (62\%). A similar study conducted by Fritzsche et al. on pathologists in Switzerland also revealed prevalence of musculoskeletal problems, which was as high as $76 \%$ [3]. It is interesting to note that these problems were faced by many young microscope users too, which argues against a mere aging effect of this disorder. Being repetitive in many, it also forced some microscope users to be absent from work for 1-2 days. According to the National Safety Council 2006, musculoskeletal injuries could result in loss of median 10 working days ( $>8$ median working days lost for all injuries) [5].

The most common locations of musculoskeletal problems in our study were neck and back, similar to a study by Lorusso et al. on musculoskeletal complaints among microscope workers [9]. Other problematic areas included shoulder, wrist and hand. The study by Fritzsche et al. found neck and shoulders to be the most common locations, apart from other locations like hips, face/head, ankles etc. [3]. Other surveys on cytotechnologists reported high prevalence of pain of neck, upper back, lower back, shoulder and upper extremities [10,11]. Kreczy et al. studied the pattern of musculoskeletal disorders in microscope users and found it to be associated with non-ergonomic microscope workstations, which contribute to increased muscle strain (especially in trapezius, T8, L3 and biceps brachii), fatigue, and pain with sustained work [7].

Prevalence of musculoskeletal problems was found in maximum numbers in those using microscope for 11-15 years, while smaller numbers of subjects reported musculoskeletal problems in the groups using microscope for more than 15 years. These findings were not as expected, but 
could be due to reduced time taken by these microscope users in diagnosis owing to more than 15 years of experience. Flavin et al. in a similar study found a lack of association between the number of working years and musculoskeletal problems, but they also reported a higher incidence of musculoskeletal problems in those who worked for less than 15 years [12].

In the present study, increased working hours were associated with musculoskeletal problems with all subjects of the group using microscope for more than $30 \mathrm{~h} /$ week complaining of some or the other form of musculoskeletal problem. This was probably due to prolonged static load, repetitive movements and awkward postures. Falla proved by surface electromyography that neck and back muscles were constantly working when one sits down to view slides at microscope [13].

Centre for disease control and prevention (CDC) guidelines for microscope use do not allow the microscope users to work for more than $5 \mathrm{~h}$ per day [4]. It also advises to take frequent short breaks from microscopy work [4]. In the present study, the habit of taking regular short breaks did not show significant association with lower levels of musculoskeletal complaints. The explanation for this finding could be the development of habit of regular breaks only after the problem started, incorrect technique of doing it or not providing accurate information in the questionnaire.

We found a lack of association of an ergonomic workplace setting with lower prevalence of musculoskeletal problems, the results being similar to the study by Lorusso et al. [9]. This could probably be due to procurement of ergonomic equipment after developing musculoskeletal disorders, adaptation and continuation of using wrong postures in the ergonomic work settings or lack of awareness despite the equipment. In contrast to our findings, Thompson et al. adjudged that basic ergonomic training and use of ergonomic aids could substantially decrease musculoskeletal problems [11].
On assessment of awareness levels among subjects, $38 \%$ were ignorant about work place ergonomics and $64 \%$ did not have the slightest clue about CDC guidelines for microscope use. Darragh et al. evaluated the effect of occupational therapy ergonomics intervention on the workstation design and body positioning of microscope workers and found that there was a statistically significant improvement in groups enrolled in educationtraining programme and education only programme, as compared to control group [5]. This demonstrates the need for education and training regarding ergonomic workplace settings and for modifications in microscopes being used [5].

Most light microscopes have eye piece fixed at acute angles relative to microscope body, which forces the user to flex the neck and upper back to view through the eye piece [4]. An ergonomic microscope with adjustable eyepiece, now commercially available, would allow the user to maintain neutral position of neck and upper back [4]. Although in most settings they have not replaced the traditional fixed angle microscopes due to the high purchase price [4]. When the neck is in flexed position for prolonged times, extensor muscles, tendons and ligaments are stretched, becoming lax and weak. This may lead to extensor muscle dysfunction after many years of this practice [4].

In our study group, $60 \%$ subjects declared suffering from refractive errors. According to a study by Fritzsche et al. on pathologists in Switzerland, about $90 \%$ of the occupational group suffered from ametropia and more than $50 \%$ had experienced an aggravation during their working years on microscope [3]. Similarly in our study, $60 \%$ ametropic microscope users reported an aggravation of ametropia during their working years, out of which $33.3 \%$ believed that microscope use was the sole reason for this aggravation. The relationship between higher myopia prevalence and occupations with extensive near-field work requirements is well documented, yet the conventional myopia 
might present in these individuals in the same manner as in any other person not involved with that type of work [3,14,15]. Korniushina conducted a study on microscope users, subjects working with magnifying glasses, and computer users and found that the highest overstrain was observed after 4 years of work in microscope operators who might develop professional myopia due to deprivation of accommodation [16]. A clinical study by Risovic et al., to determine the presence of refractive errors and binocular dysfunction in a population of university students with heavy near visual demands found it to be the most important factor for higher incidence of myopia, worse convergence, and exophoria [17]. The limitation of our study was that the other factors like long hours of computer work and the possibility of ametropic students entering these professions in greater numbers could not be ruled out.

Ninety four percent of subjects in our study reported some form of visual problem or a combination, ranging from eye discomfort, headache, dry eye, with maximum subjects complaining of eye fatigue during microscope use. A similar questionnaire study in Ireland by Flavin et al. highlighted that $56 \%$ of the pathology laboratory personnel suffered from visual problems associated with microscope use, including eye fatigue, eye discomfort, headache, dry eyes, dizziness and nausea [12]. Visual fatigue and discomfort may be a result of difficulty in accommodation and convergence of eye, monotonous work or working without break for prolonged periods [8].

Apart from the musculoskeletal and visual problems, microscope users in our study also complained of getting stressed with long working hours on microscope, lack of achievement of final diagnosis, reporting of microscopic findings and medico-legal complications that could arise with each case. According to a study by Fritzsche et al., every eighth pathologist in Switzerland suffered from burnout and depression and older pathologists were at higher risks [3]. We noted increased levels of stress in those using microscope for more hours, which could have been due to increased physical fatigue and monotony of work. But according to the questionnaire, only $26 \%$ subjects believed that stress was due to physical fatigue only.

Twenty six percent felt depressed and burnouted after using microscope, with maximum in subjects belonging to the group using microscope for more than $30 \mathrm{~h}$. This percentage was much higher than that found by Fritzsche et al. (6.7\% and $8.6 \%$, respectively) [3]. Despite the results, Fritzsche et al. found burnout and depression to be the most common mental disease of pathologists [3]. In the present study, $74 \%$ subjects were satisfied with the comfort levels of their workplace regardless of the fact whether it was ergonomically optimized or not. The reasons given were presence of basic facilities like windows in reporting rooms (some having air-conditioners), sufficient and comfortable sitting area, adjustable chairs in some labs and provision of regular servicing of microscopes. It could also be explained as ignorance turned into bliss.

Despite the above issues, most microscope users who took part in this study were optimistic about their work atmosphere, similar to the study by Fritzsche et al. [3].

\section{CONCLUSION}

The most common occupational concerns of microscope users were musculoskeletal problems of neck and back regions, eye fatigue, aggravation of ametropia, headache, stress due to long working hours and anxiety during or after microscope use. Awareness about workplace ergonomics and CDC guidelines was poor and many subjects in the study did not have ergonomically optimized microscope and workplace. This study found the immediate need for increasing awareness about the various occupational hazards that can affect the microscope users so that they become alert about the risks and start taking all necessary precautions to prevent them. 


\section{REFERENCES}

1. Menaghan EG, Merves ES. Coping with occupational problems: The limits of individual efforts. J Health Soc Behav. 1984;25:406-23, http://dx.doi.org/10.2307/2136379.

2. Oxforddictionaries.com [Internet]. New York: Oxford University Press; 2000 [updated 2014 June; cited 2013 Dec 2]. Available from: http://www.oxforddictionaries.com/definition/american_english/occupational-hazard.

3. Fritzsche FR, Ramach C, Soldini D, Caduff R, Tinguely M, Cassoly E, et al. Occupational health risks of pathologists Results from a nationwide online questionnaire in Switzerland. BMC Public Health. 2012;12:1054, http://dx.doi. org/10.1186/1471-2458-12-1054.

4. George E. Occupational hazard for pathologists. Microscope use and musculoskeletal disorders. Am J Clin Pathol. 2010;133:543-8, http://dx.doi.org/10.1309/AJCPUXDS5KJKRFVW.

5. Darragh AR, Harrison H, Kenny S. Effect of an ergonomics intervention on workstations of microscope workers. Am J Occup Ther. 2008;62(1):61-9, http://dx.doi.org/10.5014/ ajot.62.1.61.

6. Osha.gov [Internet]. Washington DC: United States Department of Labor [cited 2013 Dec 2]. Available from: https:// www.osha.gov/SLTC/ergonomics/index.html.

7. Kreczy A, Kofler M, Gschwendtner A. Underestimated health hazard: Proposal for an ergonomic microscope work station. Lancet. 1999;354(9191):1701-2， http://dx.doi.org/10.1016/ S0140-6736(99)03131-1.

8. Franco G. Health disorders and ergonomic concerns from the use of the microscope: A voice from the past. Am J Clin Pathol. 2011;135:170-1, http://dx.doi.org/10.1309/AJCPUYF00YHFHTHJ.
9. Lorusso A, Bruno S, Caputo F, LAbbate N. Risk factors for musculoskeletal complaints among microscope workers. G Ital Med Lav Ergon. 2007;29(4):932-7.

10. Kalavar S, Hunting KL. Musculoskeletal symptoms among cytotechnologists. Lab Med. 1996;11:765-9.

11. Thompson SK, Mason E, Dukes S. Ergonomics and cytotechnologists: Reported musculoskeletal discomfort. Diagn Cytopathol. 2003;29:364-7, http://dx.doi.org/10.1002/ dc.10377.

12. Flavin RJ, Guerin M, O'Briain DS. Occupational problems with microscopy in the pathology laboratory. Virchows Arch. 2010;457(4):509-11, http://dx.doi.org/10.1007/s00428010-0965-x

13. Falla D. Unravelling the complexity of muscle impairment in chronic neck pain. Man Ther. 2004;9:125-33, http://dx.doi. org/10.1016/j.math.2004.05.003.

14. Ting PWK, Schmid KL, Lam CSY, Edwards MH. Objective real-time measurement of instrument myopia in microscopists under different viewing conditions. Vision Res. 2006;46(15):2354-62, http://dx.doi.org/10.1016/j.visres. 2006.01.014.

15. McBrien NA, Adams DW. A longitudinal investigation of adult-onset and adult-progression of myopia in an occupational group: Refractive and biometric findings. Invest Ophthalmol Vis Sci. 1997;38(2):321-33.

16. Korniushina TA. Physiological mechanisms of the etiology of visual fatigue during work involving visual stress. Vestn Oftalmol. 2000;116(4):33-6.

17. Risovic DJ, Misailovic KR, Eric-Marinkovic JM, KosanovicJakovic NG, Milenkovic SM, Petrovic LZ. Refractive errors and binocular dysfunctions in a population of university students. Eur J Ophthalmol. 2008;18(1):1-6.

This work is available in Open Access model and licensed under a Creative Commons Attribution-NonCommercial 3.0 Poland License - http://creativecommons.org/ licenses/by-nc/3.0/pl/deed.en. 